\title{
PERGERAKAN DISTRIBUSI MATRIK ASAL TUJUAN TRANSPORTASI BARANG INTERNAL DI PROVINSI DAERAH ISTIMEWA YOGYAKARTA
}

\author{
Herna Puji Astutik \\ Jurusan Teknik Sipil Fakultas Teknik Sipil dan Perencanaan \\ Institut Teknologi Nasional Yogyakarta \\ E-mail : herna@itny.ac.id
}

\begin{abstract}
ABSTRAK
Transportasi merupakan bagian penting dalam pembangunan dan pengembangan suatu daerah. Perencanaan Transportasi membutuhkan data Pergerakan Asal-Tujuan. Data pergerakan/asal tujuan barang digunakan sebagai bahan analisis untuk merumuskan kebijakan transportasi dalam usaha memfasilitasi demand pergerakan barang. Proses rekapitulasi data asal-tujuan antar Kabupaten di Provinsi Daerah Istimewa Yogyakarta sangat diperlukan, agar data pola pergerakan barang mudah dikelola dan bermanfaat bagi pihakpihak yang berkepentingan. Metode Penelitian ini menggunakan metode penelitian kuantitatif deskriptif dengan pendekatan Analisis Data Sekunder (ADS). Data yang digunakan dalam Penelitian ini adalah data survei yang telah dilakukan oleh Kemenhub Badan Penelitian dan Pengembangan Perhubungan Survei Asal Tujuan Transportasi Barang pada tahun 2018. Berdasarankan hasil olahan data Origin-Destination Provinsi DIY bahwa pergerakan distribusi perjalanan asal terbesar adalah dari Kabupaten Sleman ke Seluruh Kabupaten di Provinsi DIY adalah 157995 ton/bulan. Untuk distribusi tujuan terbesar adalah Kabupaten Sleman yang didistribusi dari seluruh Kabupaten di DIY pula, dengan besar nilai distribusi tujuan adalah 128626 ton/bulan.
\end{abstract}

Kata Kunci : Transportasi Barang, Data Pergerakan Asal-Tujuan, Provinsi DIY

\section{ABSTRACT}

Transportation is an essential part of the development of an area. Transportation Planning requires Origin-Destination Movement data. Movement data/origin of goods is material for analysis to formulate transportation policies facilitating the movement of goods demand. The recapitulation of origin-destination data process between regencies in Yogyakarta is vital so data patterns of movement of goods are easily managed and useful for interested parties. This study used a descriptive quantitative research method with the Secondary Data Analysis (ADS) approach. The data used in this research were survey data from the Ministry of Transportation Research and Development Transportation Survey of the Origin-Destination of Goods Transportation in 2018. The Origin-Destination data of Yogyakarta suggest that the movement of the most significant origin of travel distribution is from Sleman Regency to all regencies in DIY with 157995 tons/month. The most considerable destination distribution is Sleman Regency, distributed from all regencies in DIY Province, with 128626 tons/month.

Keywords: Goods Transportation, Origin-Destination Movement Data, DIY Province 


\section{PENDAHULUAN}

Meningkatnya pertumbuhan ekonomi masyarakat di Provinsi Daerah Istimewa Yogyakarta yang tercermin dengan semakin tingginya tingkat mobilitas/distribusi barang. Meningkatnya jumlah penduduk membuat kebutuhan bertambah sehingga permintaan dan distribusi barang juga meningkat. Yogyakarta memiliki banyak predikat sebagai kota, dan memiliki karakteristik khusus transportasi (Ansusanto, 2014). Oleh karena itu dibutuhkan angkutan barang yang berdimensi besar yang dapat membawa barang dalam kuantitas yang besar seperti truk - semi - trailer di wilayah konsumen yang berbeda-beda (Aruperes, 2018). Proses distribusi barang menjadi salah satu proses pergerakan ekonomi yang tidak lepas dengan pola distribusi barang antar beberapa wilayah yang diwakilkan dalam kegiatan transportasi. Transportasi merupakan bagian yang penting dalam pembangunan dan pengembangan suatu daerah. Distribusi komoditi antar wilayah masih menunjukkan ketimpangan volume muatan antara wilayah Barat Indonesia, dalam hal ini Pulau Jawa dan untuk mengetahui kondisi tersebut, maka perlu diidentifikasi dan dianalisis pola pergerakan (asal-tujuan) komoditi utama berbasis pangan antar wilayah (Perdana, 2016). Bagi praktisi, kecepatan, kepadatan dan arus lalulintas merupakan tiga parameter yang penting baik pada saat perancangan (planning), perencanaan (desain) atau operasional fasilitas jalan. Salah satu data yang dibutuhkan dalam tiga parameter adalah data pergerakan/asal tujuan barang. Data asal tujuan transportasi barang menggambarkan demand pergerakkan barang di masyarakat. Selain data asal tujuan, data bangkitan tarikan juga diperlukan. Bangkitan dan tarikan pergerakan adalah tahapan pemodelan yang memperkirakan jumlah pergerakan yang berasal dari suatu zona atau tata guna lahan dan jumlah pergerakan yang tertarik ke suatu tata guna lahan atau zona (Kumaat, 2013). Data tersebut digunakan sebagai bahan analisis untuk merumuskan kebijakan-kebijakan transportasi dalam usaha memfasilitasi demand pergerakan barang. Kebijakan-kebijakan transportasi tadi digunakan untuk memperbaiki perangkat transportasi sebagai bentuk intervensi dari sisi supply pada jaringan jalan. Jaringan Jalan, sebagai aset infrastruktur vital, harus dikelola dengan baik. Oleh karena itu, Jaringan Jalan harus dikelola dengan baik sesuai prinsip Manajemen Aset Infrastruktur. Salah satu prinsip dasar Manajemen Aset Infrastuktur adalah infrastruktur harus disediakan untuk memenuhi kebutuhan infrastruktur atau permintaan infrastruktur. Jadi pengembangan Jaringan Jalan harus didasarkan pada Permintaan Lalu-Lintas (Suprayitno \& Soemitro 2018). Pola pergerakan dalam sistem transportasi sering dijelaskan sebagai arus pergerakan (kendaraan, penumpang dan barang) yang bergerak dari zona asal ke zona tujuan di dalam daerah dan periode waktu tertentu. Matriks Asal Tujuan (MAT) sering digunakan untuk menggambarkan pola pergerakan tersebut dan dapat digunakan dalam analisis kebijakan transportasi agar tercipta pergerakan barang yang lancar (cepat), murah, aman, hemat energi dan ramah lingkungan, sehingga pelaku ekonomi dapat berkembang dan target pertumbuhan ekonomi bisa tercapai. Pola pergerakan dalam proses distribusi sangat erat kaitanya, proses distribusi komoditi yang optimal diciptakan melalui integrasi berbagai proses dari hulu hingga hilir. Integrasi tersebut harus dapat memberikan nilai tambah dari masing-masing proses (Mills, et al, 2004). Hasil penelitian dari Wong, et al, (2015) memberikan bukti bahwa integrasi terbukti mampu meningkatkan kinerja logistik. Data asal tujuan transportasi barang juga dapat dimanfaatkan oleh berbagai pihak sebagai dasar bagi perumusan kebijakan dari berbagai sektor. Berdasarkan matriks asal tujuan yang akan dianalisis, akan didapatkan besar bangkitan pergerakan dari angkutan barang, hasil keluaran dari perhitungan bangkitan lalu lintas berupa jumlah kendaraan, orang, atau angkutan barang per satuan waktu, misalnya 
kendaraan/jam. Kita dapat dengan mudah menghitung jumlah orang atau kendaraan yang masuk atau keluar dari suatu luas tanah tertentu dalam satu hari (atau satu jam) untuk mendapatkan bangkitan pergerakan (Arifin, 2019). Agar data pola pergerakan barang mudah dikelola dan juga bermanfaat bagi pihak-pihak yang berkepentingan, maka barang dikelompokkan. Barang dibagi ke dalam 33 kelompok barangsesuai Keputusan Menteri Perhubungan KM 71 tahun 2005 tentang "Pengangkutan Barang/Muatan antar Pelabuhan Laut di dalam Negeri”. Pengelompokkan barang adalah seperti terlihat pada Table 1 berikut :

Tabel 1. Pembagian Kelompok Barang

\begin{tabular}{|c|l|c|l|}
\hline No & \multicolumn{1}{|c|}{ Kelompok Barang } & No & \multicolumn{1}{|c|}{ Kelompok Barang } \\
\hline 1 & Minyak Bumi (Crude Oil) & 18 & Gula \\
\hline 2 & Gas & 19 & Garam \\
\hline 3 & BBM (Fuel) & 20 & Buah \\
\hline 4 & Batu Bara & 21 & Sayur \\
\hline 5 & Barang Tambang Lainnya & 22 & Daging dan Ternak \\
\hline 6 & Kayu Gelondongan dan Produk Hutan & 23 & Ikan \\
\hline 7 & Pengolahan Kayu dan Produk Hutan & 24 & Biji-Bijian Pertanian \\
\hline 8 & CPO & 25 & Biji-Bijian Lainnya \\
\hline 9 & Minyak Goreng & 26 & Kopi \\
\hline 10 & Bahan Kimia & 27 & Beras \\
\hline 11 & Pupuk & 28 & General Cargo Makanan \\
\hline 12 & Semen & 29 & Karet \\
\hline 13 & Pasir Besi dan Biji Besi & 30 & Tekstil \\
\hline 14 & Besi dan Baja & 31 & General Cargo Non Makanan \\
\hline 15 & Suku Cadang & 32 & Elektronika Telekomunikasi dan Audio \\
\hline 16 & Kendaraan Roda 2 dan 3 & 33 & Elektronika Rumahan dan Kantor \\
\hline 17 & Kendaraan Roda 4 dan Lebih & & \\
\hline
\end{tabular}

Untuk menciptkan jaringan transportasi angkutan barang yang baik, maka proses rekapitulasi data OD antar Kabupaten di Provinsi Daerah Istimewa Yogyakarta sangat diperlukan, agar data pola pergerakan angkutan barang di Provinsi Daerah Istimewa Yogyakarta mudah dikelola dan juga bermanfaat bagi pihak-pihak yang berkepentingan. Sehingga penulisan jurnal ini diharapkan dapat menjadi reverensi bagi pihak-pihak yang berkepentingan untuk mengambil keputusan terhadap beberapa komoditi di Kabupaten Sleman, yang diharapkan dapat meningkatkan Pendapatan Daerah Kabupaten Sleman.

\section{METODOLOGI PENELITIAN}

Metode Penelitian ini menggunakan metode penelitian kuantitatif deskriptif dengan pendekatan Analisis Data Sekunder (ADS). ADS merupakan suatu metode dengan memanfaatkan data sekunder sebagai sumber data utama. Memanfaatkan data sekunder yang dimaksud yaitu dengan menggunakan sebuah uji statistik yang sesuai untuk mendapatkan informasi yang diinginkan dari tubuh materi atau dari data yang sudah matang yang diperoleh dari Instansi atau Lembaga (seperti BPS, Departemen atau Lembaga Pendidikan) tertentu untuk kemudian diolah secara sistematis dan objektif. Data Sekunder yang digunakan dalam Penelitian ini adalah data survei yang telah dilakukan oleh Kementrian Perhubungan Badan 
Penelitian dan Pengembangan Perhubungan Survei Asal Tujuan Transportasi Barang pada tahun 2018. Selanjutnya dilakukan inventarisasi dan menggambarkan hasil inventarisasi tersebut dalam aplikasi untuk dapat diberikan simpulan dari hasil yang ada.

\section{HASIL DAN PEMBAHASAN}

MAT (Matrik Asal Tujuan) merupakan matriks berdimensi dua yang berisi informasi mengenai besarnya pergerakan antar lokasi (zona) di dalam daerah tertentu. Estimasi Matriks Asal Tujuan digunakan untuk mengetahui distribusi perjalanan guna menganalisa kinerja jaringan jalan Kota (Sutrisni, 2014). Inventarisasi MAT (Matrik Asal Tujuan)) Internal Provinsi Daerah Istimewa Yogyakarta Dari hasil olah data survei yang telah dilakukan oleh Kementrian Perhubungan Badan Penelitian dan Pengembangan Perhubungan Survei Asal Tujuan Transportasi Barang pada tahun 2018 terlihat dalam Tabel 1. Dalam Tabel 1 dapat terlihat distribusi kelompok barang yang dikategorikan dalam kelompok barang yang digunakan pada Keputusan Menteri Perhubungan KM 71 tahun 2005 tentang "Pengangkutan Barang/Muatan antar Pelabuhan Laut di dalam Negeri" yang didistribusikan antar kabupaten di Provinsi DIY, dimana SL mewakili Sleman, BT mewakili Bantul, GK mewakili Gunung Kidul, KULON mewakili Kuloprogo dan YK mewakili kota Yogyakarta. Didalam tabel tersebut menyajikan jumlah pergerakan masing-masing barang dalam satuan ton.Dari hasil survei yang telah dilakukan oleh Kementrian Perhubungan Badan Penelitian dan Pengembangan Perhubungan Survei Asal Tujuan Transportasi Barang pada tahun 2018 dapat dilihat bahwa komoditi General Cargo makanan memegang jumlah terbesar sebesar 132694 ton disusul Minyak Goreng sebesar 88492 ton dan Beras dengan jumlah 21538 ton. Dan untuk distribusi terbesar diraih oleh pendistribusian kabupaten Sleman ke Sleman dengan nilai distribusi dari 33 komoditi tersebut adalah 92803 ton disusul Bantul ke Bantul 59886 ton dan peringkat ketiga distribusi terbanyak adalah Kabupaten Sleman ke kabupaten Yogyakarta sebesar 24813 ton. Untuk dapat lebih jelasnya lagi dapat dilihat direkapitulasi Matriks Asal Tujuan Barang yang dari hasil survey yang telah dilakukan pada Tabel 2. berikut ini

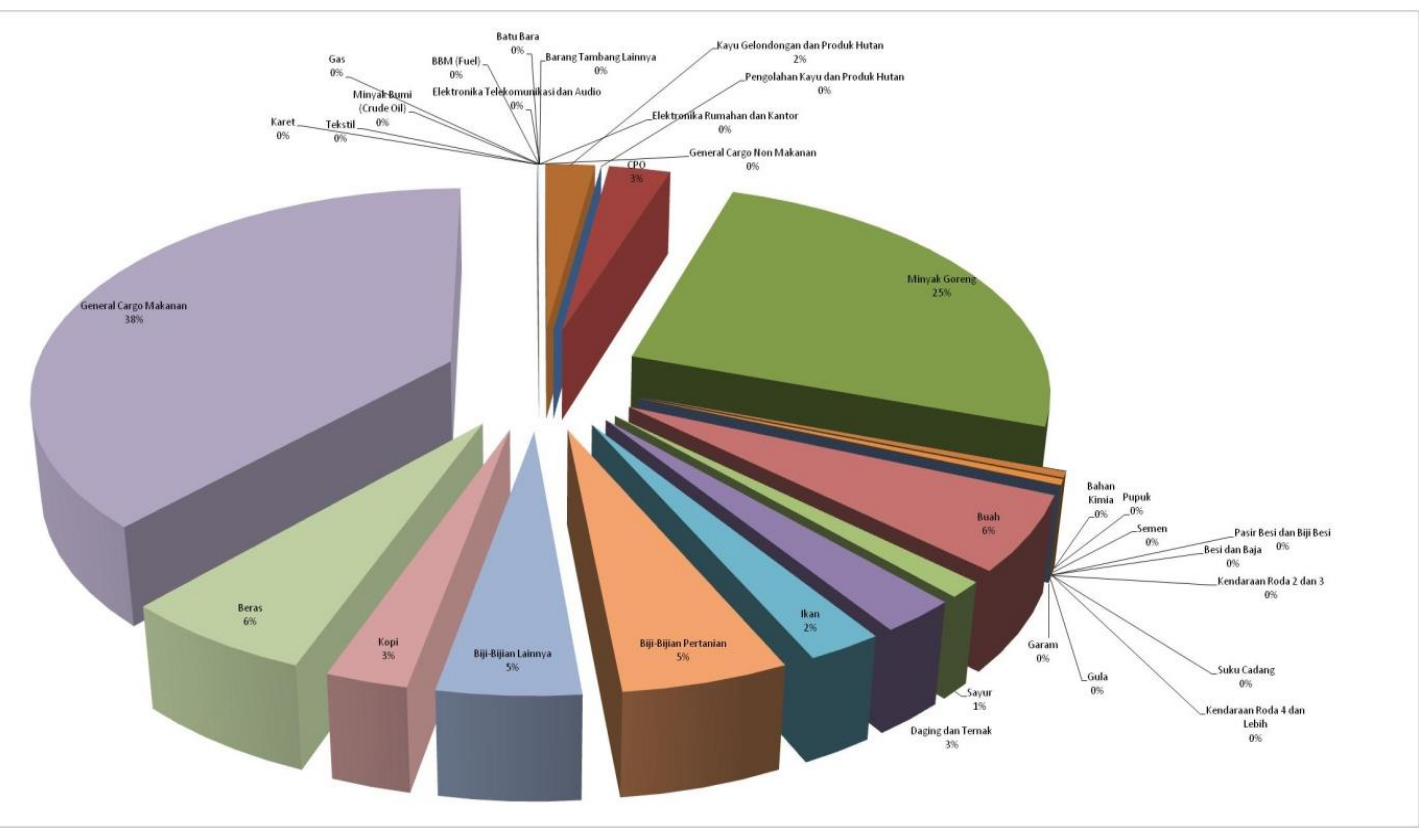

Gambar 1. Prosentase Barang Yang Ddistribusikan di DIY 
JURNAL KACAPURI

JURNAL KEILMUAN TEKNIK SIPIL

Volume 3 Nomor 2 Edisi Desember 2020

Tabel 2. Distribusi Kelompok Barang Antar Kabupaten di DIY

\begin{tabular}{|c|c|c|c|c|c|c|c|c|c|c|c|c|c|c|c|c|c|c|c|c|c|c|c|c|c|c|}
\hline Vo $\quad$ Kelompok Barang & SL-SL & SL-BT & SL-GK & SL-KULON & SL-YK & BT-SL & вт-вт & BT-GK & Bт-KULON & BТ-УK & GK-SL & GK-BT & GK-GK & GK-KULon & GK-КYK & KULON-SL & KULON-BTS & TLLULON-GK & K/LON-KUL & GKULON-YK & YK-SL & ҮК-втL & ҮК-GK & YK-KULON & YK. YK & JUMLAH \\
\hline Minyak Bumi (Crude Oil) & 0 & 0 & 0 & 0 & 0 & 0 & 0 & 0 & 0 & 0 & 0 & 0 & 0 & 0 & 0 & 0 & 0 & 0 & 0 & 0 & $0^{0}$ & 0 & 0 & 0 & $e_{0}$ & 0 \\
\hline Gas & $0^{0}$ & 0 & 0 & 0 & 0 & 0 & 0 & 0 & $e_{0}$ & $0^{0}$ & 0 & 0 & $0_{0}$ & $0^{0}$ & 0 & 0 & 0 & 0 & $0^{0}$ & 0 & 0 & $0^{0}$ & $0^{0}$ & 0 & 0 & 0 \\
\hline (BBM (Fuel) & $0^{0}$ & 0 & 0 & 0 & $0^{0}$ & 0 & 0 & 0 & $0_{0}$ & 0 & 0 & 0 & 0 & $0^{0}$ & 0 & 0 & 0 & $e_{0}$ & $0^{0}$ & $0_{0}$ & 0 & 0 & $0^{0}$ & 0 & $0^{0}$ & 0 \\
\hline Batu Bara & 0 & 0 & 0 & 0 & 0 & 0 & 0 & 0 & 0 & 0 & 0 & 0 & 0 & 0 & 0 & 0 & 0 & 0 & 0 & 0 & 0 & 0 & 0 & 0 & 0 & 0 \\
\hline Barang Tambang Lainnya & 0 & 0 & 0 & 0 & 0 & 0 & 0 & 0 & 0 & 0 & 0 & 0 & 0 & 0 & 0 & 0 & 0 & 0 & 0 & 0 & 0 & 0 & 0 & 0 & 0 & 0 \\
\hline Kayu Gelondongan dan Produk Hutan & 121 & 1153 & 428 & 345 & 1152 & 994 & 83 & 459 & 291 & 509 & 324 & 404 & 38 & 87 & 118 & 488 & 478 & 163 & 23 & 203 & 9 & 5 & 1 & 1 & 0 & 7877 \\
\hline Pengolahan Kayu dan Produk Hutan & 0 & 0 & 0 & 0 & 0 & 0 & 0 & 0 & 0 & 0 & 0 & 0 & 0 & 0 & 0 & 0 & 0 & 0 & 0 & 0 & 0 & 0 & 0 & 0 & 0 & 0 \\
\hline $\mathrm{CPO}$ & 152 & 1441 & 535 & 431 & 1440 & 1243 & 104 & 574 & 364 & 637 & 405 & 505 & 48 & 109 & 147 & 610 & 597 & 203 & 28 & 254 & 11 & 6 & 1 & 1 & 0 & 9846 \\
\hline Minyak Goreng & 36261 & 1439 & 553 & 409 & 1682 & 1508 & 23496 & 671 & 390 & 840 & 546 & 632 & 12486 & 130 & 216 & 1333 & 1212 & 428 & 3657 & 603 & 0 & 0 & 0 & 0 & 0 & 88492 \\
\hline \begin{tabular}{|l|l|}
0 & Bahan Kimia \\
\end{tabular} & 0 & 0 & 0 & 0 & 0 & 0 & 0 & 0 & 0 & 0 & 0 & 0 & 0 & 0 & 0 & 0 & 0 & 0 & 0 & 0 & 0 & 0 & 0 & 0 & 0 & 0 \\
\hline 1 Pupuk & 0 & 0 & 0 & 0 & 0 & 0 & 0 & 0 & 0 & 0 & 0 & 0 & 0 & 0 & 0 & 0 & 0 & 0 & 0 & 0 & 0 & 0 & 0 & 0 & 0 & 0 \\
\hline 2 Semen & 19 & 164 & 61 & 50 & 179 & 284 & 22 & 122 & 80 & 148 & 10 & 12 & 1 & 3 & 4 & 140 & 128 & 43 & 6 & 59 & 0 & 0 & 0 & 0 & 0 & 1535 \\
\hline 3 Pasir Besi dan Biji Besi & 0 & 0 & 0 & 0 & 0 & 0 & 0 & 0 & 0 & 0 & 0 & 0 & 0 & 0 & 0 & 0 & 0 & 0 & 0 & 0 & 0 & 0 & 0 & 0 & 0 & 0 \\
\hline 4 Besidan Baja & 0 & 0 & 0 & 0 & 0 & 0 & 0 & 0 & 0 & 0 & 0 & 0 & 0 & 0 & 0 & 0 & 0 & 0 & 0 & 0 & 0 & 0 & 0 & 0 & 0 & 0 \\
\hline 5 Sulu Cadang & 0 & 0 & 0 & 0 & 0 & 0 & 0 & 0 & 0 & 0 & 0 & 0 & 0 & 0 & 0 & 0 & 0 & 0 & 0 & 0 & 0 & 0 & 0 & 0 & 0 & 0 \\
\hline \begin{tabular}{|l|l|}
6 Kendaraan Roda 2 dan 3 \\
\end{tabular} & 0 & 0 & 0 & 0 & 0 & 0 & 0 & 0 & 0 & 0 & 0 & 0 & 0 & 0 & 0 & 0 & 0 & 0 & 0 & 0 & 0 & 0 & 0 & 0 & 0 & 0 \\
\hline 7 Kendaran Roda 4 dan Lebih & 0 & 0 & 0 & 0 & 0 & 0 & 0 & 0 & 0 & 0 & 0 & 0 & 0 & 0 & 0 & 0 & 0 & 0 & 0 & 0 & 0 & 0 & 0 & 0 & 0 & 0 \\
\hline 8 Gula & 19 & 168 & 61 & 50 & 179 & 284 & 22 & 122 & 80 & 148 & 10 & 0 & 1 & 3 & 4 & 140 & 128 & 43 & 6 & 6 & 0 & 0 & 0 & 0 & 0 & 1474 \\
\hline & 0 & 0 & 0 & 0 & 0 & 0 & 0 & 0 & 0 & 0 & 0 & 0 & 0 & 0 & 0 & 0 & 0 & 0 & 0 & 0 & 0 & 0 & 0 & 0 & 0 & 0 \\
\hline 0 Buah & 304 & 2884 & 1071 & 863 & 2890 & 2487 & 208 & 1147 & 727 & 1275 & 810 & 1007 & 96 & 218 & 294 & 1220 & 1192 & 406 & 57 & 508 & 22 & 11 & 3 & 3 & 0 & 19703 \\
\hline 1 Sayur & 32 & 283 & 104 & 87 & 309 & 591 & 46 & 253 & 166 & 309 & 22 & 26 & 2 & 6 & 8 & 716 & 654 & 222 & 32 & 304 & 0 & 0 & 0 & 0 & 0 & 4172 \\
\hline 2 Daging dan Temak & 160 & 1420 & 525 & 436 & 1552 & 803 & 63 & 344 & 225 & 420 & 366 & 425 & 40 & 94 & 135 & 641 & 585 & 198 & 29 & 272 & 9 & 4 & 1 & 1 & 0 & 8748 \\
\hline 3 lkan & 160 & 1420 & 525 & 436 & 1552 & 803 & 63 & 344 & 225 & 420 & 366 & 425 & 40 & 94 & 135 & 641 & 585 & 198 & 29 & 9 & 4 & 4 & 1 & 1 & 0 & 8480 \\
\hline 4 Biji-Bijian Pertanian & 278 & 2495 & 974 & 1263 & 2593 & 2257 & 179 & 1039 & 1060 & 1139 & 746 & 880 & 88 & 322 & 267 & 1102 & 1022 & 366 & 82 & 452 & 0 & 0 & 0 & 0 & 0 & 18604 \\
\hline 5 Biji-Bijän Lainyay & 244 & 2173 & 827 & 917 & 2359 & 1964 & 155 & 873 & 761 & 1024 & 624 & 728 & 71 & $\frac{222}{222}$ & 230 & 989 & 909 & 318 & 62 & 419 & 0 & 0 & 0 & 0 & 0 & 15868 \\
\hline 6 Kopi & 321 & 2917 & 1115 & 1685 & 3097 & 0 & 0 & 0 & 0 & 0 & 0 & 0 & 0 & 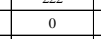 & 0 & 0 & 0 & $\frac{10}{0}$ & 0 & 0 & 0 & 0 & 0 & 0 & 0 & 9135 \\
\hline 7 Beras & 339 & 3005 & 1110 & 922 & 3284 & 2798 & 219 & 1200 & 784 & 1463 & 914 & 1062 & 101 & 235 & 339 & 1382 & 1262 & 428 & 62 & 586 & 25 & 12 & 3 & 3 & 0 & 21538 \\
\hline 8 General Cargo Makanan & 54391 & 2158 & 830 & $\frac{214}{614}$ & 2523 & 2262 & 35224 & 1006 & 585 & 1260 & 808 & 948 & 18728 & 195 & 323 & 19090 & 1818 & $\frac{426}{642}$ & 5485 & 904 & 0 & 0 & 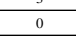 & 0 & 0 & 132694 \\
\hline 9 Karet & 0 & 0 & 0 & 0 & 0 & $\frac{2020}{0}$ & $\frac{0.24}{0}$ & 0 & $\frac{0}{0}$ & 0 & $\frac{800}{0}$ & 0 & 0 & 0 & $\frac{0}{0}$ & 0 & 0 & 0 & 0 & $\frac{34}{0}$ & 0 & 0 & 0 & 0 & 0 & 0 \\
\hline 0 Tekstil & 0 & 0 & 0 & 0 & 0 & 0 & 0 & 0 & 0 & 0 & 0 & 0 & 0 & 0 & 0 & 0 & 0 & 0 & 0 & 0 & 0 & 0 & 0 & 0 & 0 & $0_{0}$ \\
\hline 1 General Cargo Non Makanan & 2 & 20 & 8 & 4 & 22 & 26 & 2 & 11 & 5 & 13 & 13 & 15 & 1 & 2 & 5 & 18 & 17 & 6 & 1 & 8 & 65 & 31 & 8 & 5 & 1 & 309 \\
\hline Elektronika Telkkonmunikasi dan Audio & $e_{0}$ & 0 & 0 & $\frac{4}{0}$ & 0 & 0 & $0_{0}$ & 0 & 0 & 0 & 0 & 0 & 0 & 20 & 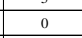 & 0 & 0 & 0 & 0 & 0 & 0 & $\frac{1}{0}$ & 0 & 0 & 0 & $\frac{3}{0}$ \\
\hline 3 Elektronika Rumahan dan Kantor & 0 & 0 & 0 & 0 & 0 & 0 & 0 & 0 & 0 & 0 & 0 & 0 & 0 & 0 & 0 & 0 & 0 & 0 & 0 & 0 & 0 & 0 & 0 & 0 & 0 & 0 \\
\hline Jumbh & 92803 & 23140 & 8727 & 8512 & 24813 & 18304 & 59886 & 8165 & 5743 & 9605 & 5964 & 7069 & 31741 & 1720 & 2225 & 11410 & 10587 & 3664 & 9558 & 4587 & 145 & 73 & 18 & 15 & 1 & 348475 \\
\hline
\end{tabular}

Sumber : Kementrian Perhubungan Badan Penelitian dan Pengembangan Perhubungan Survei Asal Tujuan Transportasi Barang pada tahun 2018 
JURNAL KACAPURI

Untuk dapat lebih jelasnya lagi dapat dilihat direkapitulasi Matriks Asal Tujuan Barang yang dari hasil survey yang telah dilakukan pada Tabel 2 berikut ini

Tabel 2. Matriks Asal Tujuan Distribusi Barang Antar Kabupten di Provinsi DIY

\begin{tabular}{|c|c|c|c|c|c|c|c|}
\hline Asal-Tujuan & $\stackrel{\text { 窎 }}{\stackrel{\Xi}{\Xi}}$ & Sleman (SL) & Bantul (BT) & Gunung Kidul (GK) & Kulonprogo (KULON) & Kota Yogyakarta (YK) & Jumlah \\
\hline Asal & & \multicolumn{5}{|c|}{ (ton/bulan) } & \\
\hline Sleman (SL) & \multirow{4}{*}{ 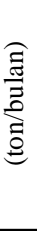 } & 92803 & 23140 & 8727 & 8512 & 24813 & 157995 \\
\hline Bantul (BT) & & 18304 & 59886 & 8165 & 5743 & 9605 & 101703 \\
\hline Gunung Kidul (GK) & & 5964 & 7069 & 31741 & 1720 & 2225 & 48719 \\
\hline Kota Yogyakarta (YK) & & 145 & 73 & 18 & 15 & 1 & 252 \\
\hline Jumlah & & 128626 & 100755 & 52315 & 25548 & 41231 & \\
\hline
\end{tabular}

\section{Matriks Asal Tujuan Angkutan Barang Di Provinsi Daerah Istimewa Yogyakarta}

Guna mewujudkan pelayanan transportasi yang efektif dan efisien, diperlukan penetapan kebijakan dan perencanaan yang tepat, dengan didukung oleh data yang akurat dan valid. Salah satu data yang dibutuhkan adalah data pergerakan/asal tujuan barang. Data asal tujuan transportasi barang menggambarkan demand pergerakkan barang di masyarakat. data tersebut digunakan sebagai bahan analisis untuk merumuskan kebijakan-kebijakan transportasi dalam usaha memfasilitasi demand pergerakan barang. kebijakankebijakan transportasi tadi digunakan untuk memperbaiki perangkat transportasi sebagai bentuk intervensi (perubahan) dari sisi supply. data asal tujuan transportasi barang digunakan dalam analisis kebijakan transportasi agar tercipta pergerakan barang yang lancar (cepat), murah, aman, hemat energi dan ramah lingkungan, sehingga pelaku ekonomi dapat berkembang dan target pertumbuhan ekonomi bisa tercapai. Data asal tujuan transportasi barang juga dapat dimanfaatkan oleh berbagai pihak sebagai dasar bagi perumusan kebijakan dari berbagai sektor.

Untuk dapat mengakomodir data distribusi angkutan barang di Daerah Istimewa Yogyakarta secara tepat dan dapat mewujudkan transportasi barang yang efisien dan efektif untuk rencana Business Plan Angkutan Barang Di Daerah Istimewa Yogyakarta dirangkum dalam Tabel 2 berupa data matriks distribusi 33 komoditi barang antar Kabupaten sesuai peraturan pada Keputusan Menteri Perhubungan KM 71 tahun 2005 tentang "Pengangkutan Barang/Muatan antar Pelabuhan Laut di dalam Negeri”.

Berdasarkan hasil analisis data asal-tujuan pergerakan barang diketahui bahwa besarnya permintaan perjalanan barang dari-ke kota tertentu dapat disimpulkan sejumlah wilayah potensial angkutan barang dengan potensi lalulintas barang yang cukup besar sebagaimana disampaikan di Tabel 2 dan di gambarkan dalam garis Desire Line yang disajikn dalam Gambar 1. Dimana hasil olah data matriks tersebut mnggambarkan lokasi Sleman memiliki angka bangkitan dan tarikan terbesar angkutan barang yang digambarkan jumlah tonnage/bulan jumlah pengiriman barang terbesa, yang disusul posisi ke 2 jumlah tonnage/bulan terbesar adalah di Kabupaten Bantul. Data ini menggambarkan pola pergerakan barang, yaitu jumlah tonnage barang yang berasal dari satu zona ke zona lainnya. Satuan yang digunakan adalah ton/bulan 


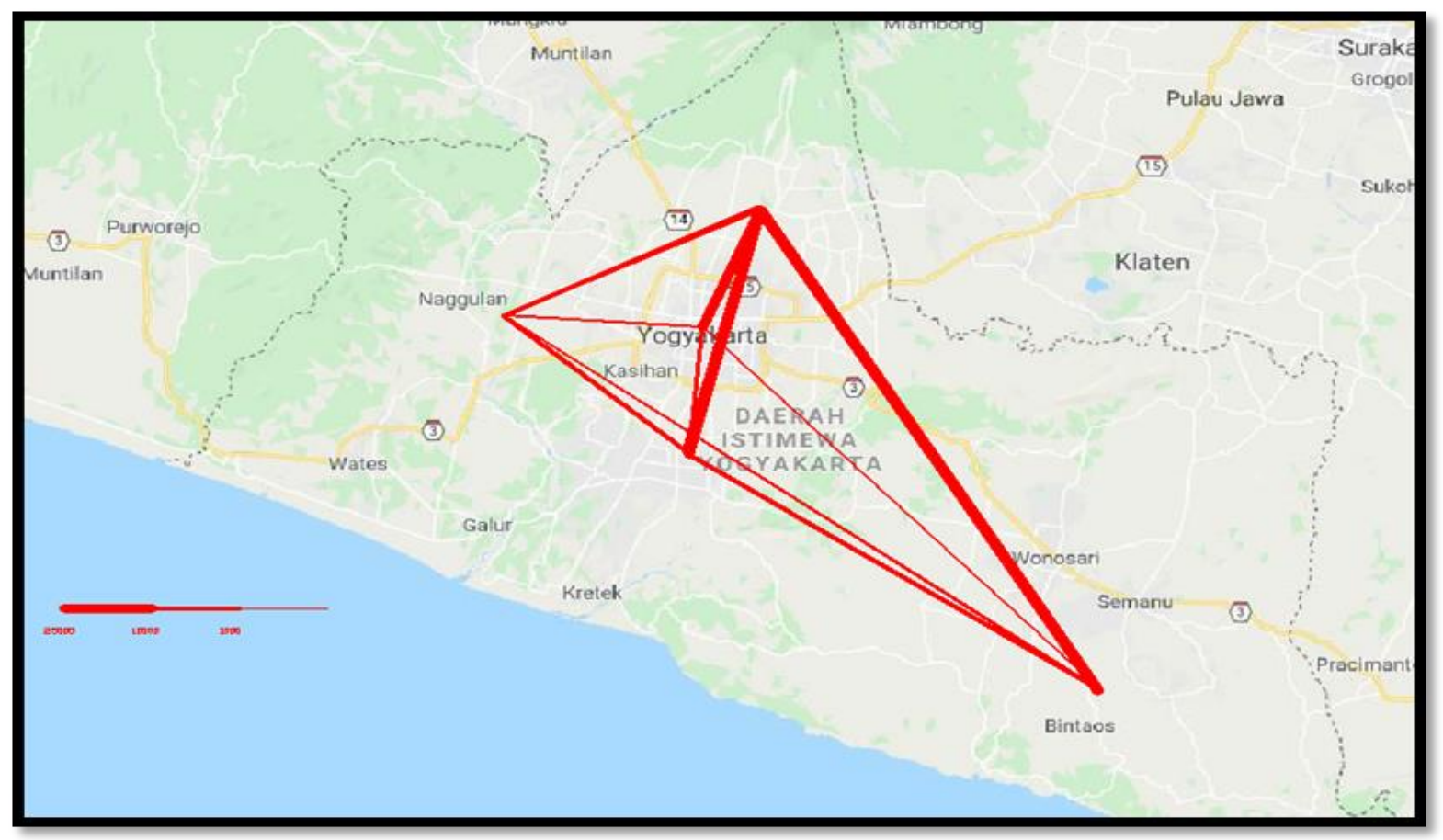

Gambar 2 Desire Line Pergerakan Barang di dalam Provinsi DIY

Besarnya pergerakan angkutan barang di Indonesia dapat direpresentasikan dengan Matriks Asal-Tujuan (MAT) ataupun dengan diagram garis keinginan (desire line). Distribusi perjalanan juga dapat direpresentasikan dalam bentuk Desire Lines, yang merupakan garisgaris yang menghubungkan antar pusat zona pada suatu peta, dengan ketebalan garis menunjukkan besaran pergerakannya. Selain itu output dari permodel simulasi jaringan jalan adalah potensi Demand yang digambarkan dalam Desire Line, dimana desire line tersebut dapat memprediksikan seberapa besar pergerakan perjalanan pada masa mendatang (Dwi, 2017). Dari sini dapat terlihat secara visual lokasi mana saja yang ramai dikunjungi. Dari Gambar Desire Line Pergerkan Barang di DIY diatas dapat dilihat bahwa arus lalulintas dan jaringan jalan terpadat adalah terjadi dari dan ke Kabupaten Sleman Daerah Istimewa Yogyakarta, dimana garis tesebut menggambarkan besaran pergerakan barang yang telah di survei oleh Kementrian Perhubungan Badan Penelitian Dan Pengembangan Perhubungan Survei Asal Tujuan Transportasi Barang Pada Tahun 2018.

\section{PENUTUP}

\section{Kesimpulan}

Berdasarankan dari hasil olahan data Origin-Destination Provinsi Daerah Istimewa Yogyakarta dari survey yang telah dilakukan Kementrian Perhubungan Badan Penelitian dan Pengembangan Perhubungan Survei Asal Tujuan Transportasi Barang pada tahun 2018, maka dapat diambil kesimpulan, bahwa pergerakan distribusi perjalanan asal terbesar adalah dari Kabupaten Sleman ke Seluruh Kabupaten di Provinsi DIY sebesar 157995 ton/bulan. Dan untuk distribusi tujuan terbesar juga jatuh pada Kabupaten Sleman yang didistribusi dari seluruh Kabupaten di DIY pula, dengan besar nilai distribusi tujuan adalah sebesar 128626 ton/bulan. 


\section{DAFTAR PUSTAKA}

[1] Arifin, Triana Sharly P., Haryanto, Budi., Ramadhani, Utari Nur. 2019. Development of Freight Trip Generation Model in East Kalimantan Province. Jurnal Manajemen Aset Infrastruktur \& Fasilitas Vol.3 Sup.1

[2] Aruperes, Gledis P., Pandey, Sisca V \& Lalamentik, Lucia G. 2018. Analisis Pergerakan Angkutan Barang Dari Kota Bitung. Jurnal Sipil Statik Vol.6 No.1 Januari 2018 (57-66) ISSN: 2337-6732

[3] Dwi, Aristian P., murtejo, tedy. 2017. Analisis Potensi Bangkitan Dan Tarikan (Studi Kasus pada Stasiun LRT Kedunghalang Kota Bogor). Jurnal Rekayasa Sipil ASTONJADRO Volume 6 Nomor 2, Desember 2017 ISSN 2302-4240

[4] https://attn-barang.dephub.go.id/, diakses 23 Juli 2020 pukul 12.50 WIB

[5] Kumaat, Meike. 2013. Analisis Bangkitan Dan Tarikan Pergerakan Penduduk Berdasarkan Data Matriks Asal Tujuan Kota Manado. Jurnal Tekno Sipil / Volume 11 / No.58 / April 2013

[6] Martono, Nanang. 2014. Metod Penelitian Kuantitatif: Analisis Isi dan Analisis Data Sekunder. Jakarta: Rajawali Pers

[7] Menhub. 2015. Keputusan Menteri Perhubungan KM 71 tahun 2005 tentang Pengangkutan Barang/Muatan antar Pelabuhan Laut di dalam Negeri.

[8] Menhub. 2018. Survei Asal Tujuan Transportasi Barang. Kementrian Perhubungan Badan Penelitian dan Pengembangan Perhubungan.

[9] Mills, J., Schmitz, J., Frizelle, G. 2004. A strategic review of "supply networks". International Journal of Operations \& Production Management, 24 (10) : 1012-1036.

[10] Perdana, Yandra Rahadian., Soemardjito, Joewono. (2016). Analisis Asal Tujuan Komoditi Utama Antar Wilayah Pulau Jawa, Kalimantan, Dan Nusa Tenggara Timur. Jurnal Penelitian Transportasi Multimoda Volume 14/No. 01/Maret/2016

[11] Priyanto, Sigit., Munawar, Ahmad., Priyanto, Sigit \& Wibisono, Bambang Hari. 2014. Pola Perjalanan Di Perkotaan Yogyakarta. Jurnal Teknik Sipil Volume 12, No. 4, April 2014: $249-258$

[12] Suprayitno, H. \& Soemitro, R.A.A. (2018). "Preliminary Reflexion on Basic Principle of Infrastructure Asset Management". Jurnal Manajemen Aset Infrastruktur \& Fasilitas, Vol. 2, No. 1, Maret 2018, Hal. : 1-9.

[13] Sutrisni, Sri., Syafi'i \& Setiono. 2014. Estimasi Matriks Asal Tujuan ( Mat ) Kota Surakarta Tahun 2025. e-Jurnal MATRIKS TEKNIK SIPIL Vol. 2 No. 2/Juli 2014/237

[14] Wong, C, W, Y., Lai, K., Bernroider, E, W, N. 2015. The performance of contingencies of supply chain information integration: The roles of product and market complexity. International Journal of Production Economics, 165:1-11 